\begin{tabular}{|l|l|l||}
\hline \multicolumn{2}{|c|}{ PublisherInfo } \\
\hline \hline PublisherName & $:$ & BioMed Central \\
\hline \hline PublisherLocation & $:$ & London \\
\hline \hline PublisherImprintName & $:$ & BioMed Central \\
\hline \hline
\end{tabular}

\title{
Infective endocarditis: a better outcome after surgery during the active phase
}

\begin{tabular}{|l|l|l||}
\hline \multicolumn{2}{|c|}{ ArticleInfo } \\
\hline \hline ArticleID & $:$ & 4221 \\
\hline \hline ArticleDOI & $:$ & $10.1186 /$ ccf-2000-6339 \\
\hline \hline ArticleCitationID & $:$ & 6339 \\
\hline \hline ArticleSequenceNumber & $:$ & 80 \\
\hline \hline ArticleCategory & $:$ & Paper Report \\
\hline ArticleFirstPage & $:$ & 1 \\
\hline \hline ArticleLastPage & $:$ & 4 \\
\hline \hline & & RegistrationDate : 2000-9-19 \\
\hline ArticleHistory & $:$ & OnlineDate \\
\hline \hline ArticleCopyright & $:$ & Current Science Ltd2000-19 \\
\hline \hline ArticleGrants & $:$ & \\
\hline \hline ArticleContext & $:$ & 1305422 \\
\hline \hline
\end{tabular}


Aff1 Clinical Hospital, Montevideo, Uruguay

\section{Keywords}

Infective endocarditis, staphylococci, streptococci

\section{Comments}

Very few studies document long term survival in infective endocarditis. This prospective study, which excluded intravenous drug abusers, recorded both 1 and 5 year mortality. The investigators found that a higher proportion of patients (51\%) underwent surgery during the active phase of the disease (when symptoms were still pronounced but the condition was stable) than those reported in other series. A delay in diagnosis and consequently in the initiation of antimicrobial treatment was associated with higher complication rates (83\%), thus requiring a greater number of surgical procedures. Unlike previous studies, the most frequent cause of early mortality was not heart failure or persistent sepsis but complications in emergency surgery. However, there was no significant difference in mortality between patients following medical treatment $(20 \%)$ or those undergoing elective surgery $(21 \%)$. Overall survival at 5 years $(71 \%)$ was higher than in other series. In conclusion the results seem to indicate that elective surgery in the active phase of infective endocarditis improves long term survival rate without increasing early mortality. Additionally, in cases of responsive infective endocarditis with absence of poor prognostic factors, medical treatment also offers favourable long term results.

\section{Introduction}

To determine the clinical features and long term prognosis of infective endocarditis in patients who were not intravenous drugs abusers.

\section{Methods}

- Prospective series with 138 consecutive cases of infective endocarditis diagnosed and treated from January 1987 to March 1997 
- Early prosthetic valve endocarditis (PVE) was diagnosed when infection occurred in the first two months following heart surgery, while intermediate and late PVE were diagnosed when infection developed at 2-12 months and more than one year, respectively

- All patients received antibiotic treatment for 4-6 weeks

- Surgery was indicated in the following circumstances: moderate to severe heart failure, significant valve regurgitation, repeated major emboli, severe mechanical complications, in cases of early PVE, endocarditis on pacemaker leads, and in cases of persistent sepsis

- Emergency surgery was that which could not be postponed for more than $24 \mathrm{~h}$. Elective surgery could be delayed for longer time periods without risk to the patient

- All survivors at the in-hospital phase were included in the prospective follow up

- Death occurring during the six weeks post-diagnosis was considered early mortality

\section{Results}

Infective endocarditis was diagnosed in 124 out of 138 cases. Native valve endocarditis (NVE) accounted for $69 \%$ of the cases and PVE $31 \%$. A presumed portal of entry was identified for $38 \%$ of the cases. Staphylococcus was the organism most frequently responsible for NVE cases, while streptococcal infection was the most common in the PVE cases. Echocardiography detected vegetations in $86 \%$ of the cases $(59 \%$ with transthoracic echocardiography and $92 \%$ with transoesophageal echocardiography $[P<$ $0.01]$ ) and this difference was greater in the PVE group than in the NVE group. Cardiac and extracardiac complications were a frequent finding (83\%). Surgery was carried out in the active phase in $50 \%$ of the cases with NVE and 53\% of the cases with PVE. Elective surgery predominated over emergency procedures (29\% vs $22 \%)$. The highest mortality rate (50\%) was registered among early PVE. Prognosis was not affected by the type of infective endocarditis (NVE or PVE) or by the site and causal agent. Overall survival was $75 \%$ at 1 year and $71 \%$ at 5 and 10 years (overall survival for NVE was $78 \%$ at 1 year and $76 \%$ at 5 years, and for PVE it was $67 \%$ and $59 \%$, respectively $[P<0.01])$. Follow-up event free survival at 1 year was $92 \%$, and $82 \%$ at 5 and 10 years. One and 5 year survival rates for survivors past active phase were $98 \%$ and $96 \%$ for cases of NVE, while in cases of PVE they were $90 \%$ and $82 \%$, respectively $(P<0.05)$. 


\section{References}

1. Castillo JC, Aguita MP, Ramírez A, Siles JR, Torres F, Mesa D, Franco M, Muñoz I, Concha M, Vallés F: Long term outcome of infective endocarditis in patients who were not drug addicts: a 10 year study. Heart. 2000, 83: 525-530.

This PDF file was created after publication. 